\title{
A LITERATURA SOBRE O ESCOLA SEM PARTIDO E OS TEMAS PRINCIPAIS: UM ESTADO DA ARTE ${ }^{1}$
}

\author{
Raquel Dias Araújo²
}

\begin{abstract}
Resumo:
O artigo apresenta um estado da arte sobre o movimento Escola sem Partido (EsP), tomando como referência uma amostra de produções científicas publicadas entre os anos de 2018 e 2020 e como ponto de partida o trabalho de Rossi e Pátaro (2020), os quais se debruçaram sobre produções relativas aos anos de 2016 a 2018. Foram revisadas 49 produções para a elaboração desse artigo, que revelaram que a doutrinação e a ideologia de gênero são categorias centrais no discurso do EsP, sendo complementadas por outras que tem uma relação umbilical com o discurso reacionário do movimento. Assim, Rossi e Pátaro (2020) agruparam quatro categorias, a saber, currículo escolar, ideologia e neutralidade, "ideologia de gênero" e implicações do EsP para docentes e discentes. Nós agrupamos sete categorias, sendo duas semelhantes às de Rossi e Pátaro, "ideologia de gênero" e neutralidade, além de doutrinação, desdemocratização versus democracia e educação democrática, criminalização do(a) professor(a), EsP como discurso/movimento reacionário e educar versus instruir. A literatura revisada revelou que o fortalecimento do EsP em 2014/2015 está relacionado com o avanço das forças conservadoras no Brasil, constituindo-se num movimento social representativo do conservadorismo na educação.
\end{abstract}

Palavras-chaves: Estado da Arte. Escola sem Partido. Doutrinação. "Ideologia de Gênero". Movimento Reacionário.

\section{LITERATURE ABOUT SCHOOL WITHOUT PARTY AND MAIN THEMES: A STATE OR ART}

\begin{abstract}
:
The article presents a state of art regarding School Without Party ("Escola sem Partido", EsP), using as reference a sample of scientific productions published between the years 2018 and 2020, and as starting point Rossi and Pátaro work (2020) which dealt with productions from between 2016 and 2018. We have revised 49 productions to write this article, revealing that gender indoctrination and ideology are central categories in EsP speech, being complemented by others that have an umbilical relation to reactionary speech of the movement. Thus, Rossi and Pátaro (2020) group four categories, namely school curriculum, ideology and neutrality, "gender ideology", and EsP implications for teachers and students. We have grouped seven categories, two like Rossi and Pátaro's, "gender ideology" and neutrality in addition to indoctrination, undemocratization versus democracy and democratic education, teacher's criminalization, EsP as speech/ reactionary movement, and to educate versus to instruct. The reviewed literature revealed that EsP fortification in 2014/2015 is related to the advance of conservative forces in Brazil, constituting a representative social movement of conservatism in education.
\end{abstract}

Keywords: State of art. School without Party. Indoctrination. “Gender ideology”. Reactionary movement.

1 Artigo produzido como resultado da pesquisa realizada durante o Estágio de Pós Doutoramento, no Programa de Pós-Graduação em História da Universidade Federal Fluminense - UFF, no período de 01 de dezembro de 2019 a 30 de novembro 2020, sob a supervisão da professora Doutora Virginia Maria de Gomes Mattos Fontes. Vale ressaltar que o Estágio de Pós Doutoramento realizou-se sob uma situação de pandemia, na qual pesquisar e escrever significa "escalar muitas montanhas!".

2 Professora Associada do Centro de Educação da Universidade Estadual do Ceará - CED/UECE. Doutora em Educação pela Universidade Federal do Ceará - UFC. Coordenadora do Grupo de Estudos Educação: Teoria e História. E-mail: raquel.dias@ @ece.br. http://orcid.org/0000-0002-6880-2419 


\section{INTRODUÇÃO}

O presente artigo tem como objetivo apresentar um estado da arte acerca do movimento Escola sem Partido (EsP), destacando seus objetivos, suas principais propostas e modos de atuação, tomando como ponto de partida o levantamento bibliográfico realizado por Rossi e Pátaro (2020), que apresenta as pesquisas a respeito do EsP no período de 2016 a 2018, no artigo intitulado "Lei da Mordaça" na Literatura Científica: Um Estado da Arte sobre o Movimento Escola sem Partido. Assim, damos sequencia a esse mapeamento trazendo à baila uma amostra das produções entre 2018 e 2020, incluindo-se o artigo referido aqui, publicado em 2020.

Rossi e Pátaro (2020) revisaram 55 produções que tratam do tema "Escola sem Partido", sendo 28 artigos, 23 capítulos de livros de duas coletâneas, 3 dissertações de mestrado e um trabalho de conclusão de curso. Destas, merecem destaque as duas coletâneas revisadas intituladas A ideologia do movimento Escola sem Partido: 20 autores desmontam o discurso (2016) e Escola "sem" partido: esfinge que ameaça a educação e a sociedade (2017), as quais já haviam sido objeto de análise nossa em momento anterior e constituíram subsídios para elaboração de artigos e trabalhos apresentados em eventos.

Para elaboração desse artigo, revisamos, além das duas coletâneas já citadas, que contém 17 e 09 capítulos, respectivamente, mais 24 produções que versam sobre a temática Escola sem Partido, sendo 18 capítulos de livro de duas coletâneas específicas sobre o objeto de análise, 01 brochura (livro de bolso) que discute a questão da ideologia no EsP, 02 artigos de Dermeval Saviani a respeito desse tema, 01 cartilha produzida pelo Sindicato Nacional dos Docentes das Instituições de Ensino Superior - ANDES-SN que contém um texto sobre o EsP e o artigo de Rossi e Pátaro (2020). Merecem destaque as duas coletâneas intituladas Educação Democrática: Antídoto ao Escola sem Partido (2018) e Escola sem Partido ou a Escola da Mordaça e do Partido Único a Serviço do Capital (2019). No total, foram revisadas 49 produções.

A coletânea intitulada Educação democrática: Antídoto ao Escola sem Partido (2018), organizada por Penna et al., contém 9 capítulos e uma apresentação feita por Marise Nogueira Ramos. Enquanto o livro anterior, Escola "sem” Partido: esfinge que ameaça a educação, organizado por Frigotto (2017), procurava decifrar o Movimento Escola sem Partido e identificar seus males, esta coletânea se apresenta como um antídoto às ideologias do

\begin{tabular}{|c|c|c|c|c|}
\hline Q Rovista Dialeatus & Ano 10 & n. 23 & Maio - Agosto 2021 & p. $279-306$ \\
\hline
\end{tabular}


pensamento único, nas quais se enquadra o EsP. Nesse sentido, a "obra é um ato e uma arma" na direção da conquista da "real democracia", conforme anuncia Ramos (2018, p. 8).

O livro intitulado Escola sem partido ou a escola da mordaça e do partido único a serviço do capital (2019), organizado por Batista et al., tem como objetivo desvelar "[...] as bases ideológicas desta organização [...] [EsP], os mecanismos de manipulação de conceitos e termos [..]”, contrapondo ao EsP "o sentido não neutro da educação e escola democráticas" (FRIGOTTO, 2019, p. 01). A coletânea é composta de 11 capítulos, dos quais foram revisados 9, um prefácio escrito por Gaudêncio Frigotto e uma apresentação feita pelos organizadores.

As categorias identificadas nas produções revisadas por Rossi e Pátaro (2020) são "currículo escolar", "ideologia e neutralidade", "ideologia e gênero" e "implicações do ESP para docentes e discentes". Nas produções revisadas por nós, identificamos as seguintes categorias sistematizadas da seguinte maneira: "doutrinação", "gênero e ideologia de gênero", “desdemocratização versus democracia e educação democrática”, “criminalização do(a) professor(a)", "EsP como discurso/movimento reacionário", "neutralidade e educar versus instruir".

É interessante apresentar algumas notas explicativas sobre o EsP para situar a sua origem e o seu fortalecimento como movimento social representativo das forças conservadoras na educação que têm um crescimento no Brasil depois de 2013, após a realização das "Jornadas de Junho", e que teve seu ápice com o golpe parlamentar de 2016, que culminou com o impeachment da presidente Dilma e a ascensão de Michel Temer à presidência da República, seguida da vitória de Jair Bolsonaro, um candidato de extrema-direita, para a Presidência da República, em 2018.

As ideias de uma suposta Escola sem Partido surgiram em 2004, pelas mãos da Organização Não-Governamental que leva o mesmo nome, presidida pelo advogado Miguel Nagib, mas só começaram a ganhar destaque em 2014/2015, quando se materializaram em projeto de lei, que propunha modificações na Lei de Diretrizes e Bases da Educação Nacional (LDB), tendo como eixo central o combate às chamadas "ideologia de esquerda e de gênero" e “doutrinação ideológica".

Em 2014, surgem os primeiros projetos de lei - PL amparados no respectivo Movimento. O primeiro dos projetos EsP foi apresentado à Assembleia Legislativa do Rio de Janeiro (RJ) pelo Deputado Estadual Flávio Bolsonaro (na época, era do PP-RJ e, atualmente, é do Republicanos), o qual havia encomendado o projeto a Miguel Nagib, tornando-se o PL $n^{\circ}$ 2.974/2014. Em seguida, seu irmão, Carlos Bolsonaro (na época, era do PP-RJ e, atualmente, é

\begin{tabular}{|l|l|l|l|l|}
\hline Govista Dialectus & Ano 10 & n. 23 & Maio - Agosto 2021 & p. 279 - 306 \\
\hline
\end{tabular}


do Republicanos) tomou a mesma iniciativa na Câmara Municipal do RJ, apresentando o PL n ${ }^{\circ}$ 867/2014. No mesmo ano, o deputado federal Erivelton Santana (PSC-BA) apresentou o PL n ${ }^{\circ}$ 7.180/2014, que propunha alterar o artigo $3^{\circ}$ da LDB, incluindo o seguinte texto inciso:

XIII - respeito às convicções do aluno, de seus pais ou responsáveis, tendo os valores de ordem familiar precedência sobre a educação escolar nos aspectos relacionados à educação moral, sexual e religiosa, vedada a transversalidade ou técnicas subliminares no ensino desses temas.

O PL n 7.180/2014 foi arquivo e, em 2015, surgiu o PL nº 867/2015 do deputado federal Izalci Lucas (PSDB-DF), que propunha alterar a LDB incluindo o Programa Escola Sem Partido - PEsP nos princípios da educação nacional, sendo o primeiro, em âmbito federal, a receber o nome de "Escola sem Partido". O referido PL sugere também “[...] afixar nas salas de aula e nas salas dos professores das escolas um cartaz 'com 70 centímetros de altura por 50 centímetros de largura, e fonte com tamanho compatível com as dimensões adotadas", contendo os “deveres dos/das professores/as”. O PL nº 867/2015 é apensado ao PL nº 7.180/2014, além de vários outros projetos tratando de temas correlatos, como, tipificação do assédio ideológico como crime, proibição de uso dos termos gênero ou orientação sexual nos planos de educação e nos currículos, proibição de uma suposta "ideologia de gênero" nas escolas etc. Atualmente, existem 22 projetos de lei apensados ao PL no $7.180 / 2014 .^{3}$

Não é toa que as propostas defendidas pelo Movimento Escola sem Partido tenham ganhado relevância no contexto de avanço das ideias conservadoras e sob o signo de um golpe que estava sendo gestado desde o período pós-jornadas de junho de 2013, que, apesar de terem como reivindicação central a diminuição das tarifas dos transportes públicos, já continham, contraditoriamente, alguns germens de ideias reacionárias, como negação dos partidos e organizações de esquerda e de suas bandeiras.

É relevante também para se compreender a natureza do movimento EsP, identificar suas inspirações e relações com outras organizações. A organização EsP foi inspirada em

3 As informações relativas aos projetos de lei podem ser encontradas no Relatório 6 anos de projetos "Escola sem Partido" no Brasil: levantamento dos projetos de lei estaduais, municipais, distritais e federais que censuram a liberdade de aprender e ensinar, elaborado por Fernanda Pereira de Moura e Renata da C. A. da Silva, a pedido da Frente Nacional Escola Sem Mordaça. 2020. Disponível em: https://www.escolasemmordaca.org.br/?p=4393. Acesso em: 01/12/2020.

\begin{tabular}{|c|c|c|c|c|}
\hline Revista Dialectus & Ano 10 & n. 23 & Maio - Agosto 2021 & p. $279-306$ \\
\hline
\end{tabular}


iniciativas semelhantes, como, No Indoctrination ${ }^{4}$ Campus Watch $^{5}$ e Creation Studies Institute $(C S I)^{6}$ nos Estados Unidos, contrárias a uma suposta doutrinação em escolas americanas. Além disso, o próprio fundador do movimento, Miguel Nagib, afirma que o projeto teria se inspirado no Código de Defesa do Consumidor.

Penna aponta que Nagib teria ligações com o Instituto Millenium, o principal think $\operatorname{tank}^{7}$ da direita brasileira, do qual foi colaborador por um período, que propaga o pensamento liberal, e teria escrito um texto chamado "Por uma escola com os valores do Millenium" (2017, p. 42). ${ }^{8} \mathrm{O}$ EsP também mantém uma forte relação com a chamada bancada religiosa da Câmara dos Deputados, uma das principais opositoras ao debate de gênero nas escolas. A Frente Parlamentar Evangélica, por exemplo, faz a defesa explícita do EsP no documento intitulado Manifesto à Nação: O Brasil para os Brasileiros, lançado em outubro de 2018, o qual subsidia a atuação da bancada evangélica na legislatura 2019 - 2022.

Como bem ressalta Moura (2018, p. 89), “[...] o movimento Escola sem Partido (EsP) está inserido num cenário mais amplo de disputa pela hegemonia no campo das políticas para educação", caracterizado como "[...] um movimento de natureza conservadora e atuação política reacionária”. Na acepção de Cunha (2016), referido pela autora, “[...] um projeto de educação reacionária, entendida aqui como a que se opõe às mudanças sociais em curso e se esforça para restabelecer situações ultrapassadas” (MOURA, 2018, p. 89).

No período pós-golpe de 2016, entramos numa fase de desestruturação do pacto social estabelecido desde a Constituição Federal de 1988 e de desconstitucionalização dos

4 No Indoctrination é um site, criado em 2002, por Luann Wright, que, segundo explicação de Lanzendorfer (2003), oferece um fórum online para os alunos postarem avisos sobre professores que parecem estar promovendo agendas sociais ou políticas na tentativa de "doutrinar" os alunos a uma forma específica de pensar. As postagens são anônimas, mas o nome da escola, o número do curso e o professor são listados. Disponível em: https://www.bohemian.com/northbay/noindoctrinationorg/Content?oid=2178716. Acesso em: 04/01/2021.

5 Campus Watch é um site, criado em 2002, por Daniel Pipes, sendo seu diretor Winfield Myers. De acordo com o site, é um projeto do Fórum do Oriente Médio, o qual "analisa e critica os estudos do Oriente Médio na América do Norte, com o objetivo de aprimorá-los". O site diz abordar principalmente cinco problemas: "falhas analíticas, a mistura da política com a erudição, a intolerância de visões alternativas, apologética e o abuso de poder sobre os estudantes". Afirma respeitar plenamente "a liberdade de expressão daqueles que debate, insistindo na sua própria liberdade de comentar as suas palavras e atos" Disponível em: http://www.campuswatch.org/article/id/377. Acesso em: 04/01/2021.

6 Creation Studies Institute (CSI) foi criado em 1988 por Tom DeRosa, que ocupa o cargo de Diretor Executivo do CSI, o qual tem a missão de "alcançar o mundo com as verdades da criação", em oposição à teoria da evolução. Disponível em: http://creationstudies.org/about-us/history-mission. Acesso em: 04/01/2021.

7 "O conceito de think tank faz referência a uma instituição dedicada a produzir e difundir conhecimentos e estratégias sobre assuntos vitais - sejam eles políticos, econômicos ou científicos", nas palavras do próprio Instituto Millenium (2009). Disponível em: https://www.institutomillenium.org.br/o-que-significa-um-thinktank-no-brasil-de-hoje/. Acesso em: 03/02021.

8 Penna (2017, p. 42) informa que esse texto encontra-se disponível no link: https://contraoescolasempartidoblog.wordpress.com/2016/06/03/a-ideologia-do-escola-sem-partido/.

\begin{tabular}{|c|c|c|c|c|}
\hline Rovista Dialectus & Ano 10 & n. 23 & Maio - Agosto 2021 & p. $279-306$ \\
\hline
\end{tabular}


direitos sociais. Nesse contexto de cerceamento das liberdades democráticas, o Movimento Escola sem Partido encontra um terreno fértil para o desenvolvimento de suas ideias.

O artigo está dividido em duas partes, além da introdução e das considerações finais. Na primeira parte, apresentamos algumas notas explicativas acerca do surgimento e desenvolvimento do movimento Escola sem Partido, da tramitação dos projetos de lei referentes ao EsP, a influência de movimentos norte-americanos sobre o EsP que têm objetivos similares, as principais ideias defendidas pelo movimento. Na segunda parte, apresentamos a revisão da literatura relativa às produções citadas tomando como eixo central a identificação dos temas centrais discutidos pelos(as) autores(as).

\section{DESDEMOCRATIZAÇÃO VERSUS DEMOCRACIA}

Iniciamos apresentando a categoria "desdemocratização versus democracia" com base nas contribuições de Salles e Silva (2018), Queiroz e Oliveira (2018) e Frigotto (2018), o qual não faz uso da terminologia, mas nos ajuda a compreender o seu significado.

Salles e Silva (2018, p. 155) explicam que o conceito de desdemocratização “[...] 284 vem sendo construído pela ciência política para tratar dos acontecimentos recentes no mundo que parecem demonstrar um esvaziamento das bases das democracias liberais modernas". O termo foi utilizado por Wendy Brown (2006), segundo nos informaram Salles e Silva (2018, p. 155), para se referir à “corrosão dessas bases a partir de uma convergência entre neoliberalismo e neoconservadorismo nos Estados Unidos de George W. Bush”. Esvaziar a substância da democracia liberal não significa extingui-la, portanto, desdemocratização seria um processo de esvaziamento das suas bases sem, no entanto, promover uma extinção formal da mesma. $\mathrm{O}$ discurso do EsP é visto por Salles e Silva (2018) como um momento desse discurso desdemocratizante.

No Brasil, a democracia ganhou substância nos anos 1980, com o processo de redemocratização e o fim da ditadura empresarial-militar, assumindo uma grande estatura na Constituição Federal de 1988. Um dos instrumentos que constituem o arsenal da democracia burguesa e que cumpre um papel importante no zelo das instituições democráticas são os partidos políticos. Apesar disso, os partidos vêm acumulando sucessivas crises de legitimidade que se originam, principalmente, dos processos de corrupção que envolvem os partidos tradicionais de todas as matizes.

\begin{tabular}{|l|l|l|l|l|}
\hline Qevista Dialectus & Ano 10 & n. 23 & Maio - Agosto 2021 & p. 279 - 306 \\
\hline
\end{tabular}


Penna (2018, p.127) ressalta que o movimento EsP se aproveita da negatividade associada atualmente aos partidos e tenta "reduzir a política à questão partidária". Nesse sentido, “[...] o apartidarismo tão destacado pelo EsP não passa de uma grande estratégia para esconder seu caráter de antagonismo ao docente que propõe uma educação emancipadora e crítica fora dos valores do mercado" (QUEIROZ; OLIVEIRA, 2018, p. 39).

A educação, como uma instituição da democracia burguesa, assume a função de “contrapor-se ao pensamento metafísico da sociedade feudal, dominado pela Igreja e pelo Estado absolutista; e reproduzir os conhecimentos, valores e atitudes necessárias à construção e reprodução do sistema capitalista”, ou seja, a atual forma escolar tem sua gênese histórica associada à "necessidade da crescente divisão social e técnica do trabalho e do conhecimento vinculado à base dos processos produtivos" (FRIGOTTO, 2018, p. 16).

No texto constitucional brasileiro de 1988, a educação é alçada a um direito de todos e dever do Estado, sustentada pelos princípios da liberdade de aprender, ensinar, divulgar o conhecimento e o respeito ao pluralismo de ideias e concepções pedagógicas.

O artigo 205 estabelece que a educação assuma a finalidade de propiciar o pleno desenvolvimento da pessoa e o seu preparo para o exercício da cidadania. Queiroz e Oliveira (2018, p. 40) observam que sem "[...] desenvolvimento pleno da pessoa fica prejudicado o exercício da cidadania e, consequentemente, inviabiliza-se a efetiva participação democrática".

O artigo 206 define os princípios sob os quais o ensino será ministrado. Destacamos aqui dois princípios que são deturpados pelo EsP e contra os quais se insurge:

[...]

II - liberdade de aprender, ensinar, pesquisar e divulgar o pensamento, a arte e o saber; III - pluralismo de ideias e de concepções pedagógicas, e coexistência de instituições públicas e privadas de ensino.

[...] (BRASIL, 1988).

Esse processo que os(as) autores(as) denominam de desdemocratização se expressaria, na negação do ideário liberal da escola, que a burguesia representou, enquanto classe revolucionária, "como uma instituição pública, gratuita, universal e laica", a qual tinha uma dupla função, a saber, "desenvolver uma nova cultura, integrar as novas gerações na sociedade moderna e socializar, de forma sistemática, o conhecimento socialmente produzido". Como consequência, resulta na negação dos princípios associados a esta concepção - liberdade de aprender, de ensinar, pesquisar e divulgar o pensamento, a arte e o saber e o pluralismo de ideias e de concepções pedagógicas. O EsP, na contramão desse ideário liberal de educação,

\begin{tabular}{|l|l|l|l|l|}
\hline Govista Dialectus & Ano 10 & n. 23 & Maio - Agosto 2021 & p. 279 - 306 \\
\hline
\end{tabular}


equipara pensamento crítico à doutrinação, contrapõe liberdade de ensinar e aprender, advoga um pensamento único contra o pluralismo de ideias e de concepções pedagógicas.

Nesse sentido, o EsP caracteriza-se por ser um movimento reacionário, que requenta uma proposta de censura com mobilização (inclusive religiosa) que se aproxima enormemente das práticas de cunho nazista ou fascista, quando qualquer coisa que destoasse do catecismo deles era considerado como inimigo, comunista, judeu ou como proveniente de alguma raça impura. Não se trata de nenhuma liberdade, mas da imposição brutal - através da censura, penalização, desqualificação, ameaça de desemprego, ameaças físicas etc. - de uma única linha de pensamento que se apresenta como se fosse "neutra" e "representa o mais pragmático, fragmentário, restrito e obscurantista na formação de gerações" (FRIGOTTO, 2018, p. 23).

\section{ESP COMO DISCURSO / MOVIMENTO REACIONÁRIO}

Aqui, passamos a desenvolver a categoria "EsP como discurso / movimento reacionário", que foi discutida por Frigotto (2018), Rosa (2018), Saviani (2017), Saviani (apud Hermida; Lira, 2018), Conti e Piolli (2019), Silva Jr. e Fargoni (2019), Orso (2019), Carvalho (2019) e Silveira e Orso (2019).

Frigotto (2018, p.20) faz uma série de reflexões acerca das determinações que possibilitaram o ressurgimento "da esfinge do neofascismo e neonazismo a partir da década de 1970" que podem ser resumidas na seguinte questão:

\footnotetext{
Que determinações históricas conduziram à regressão das relações sociais capitalistas com a negação de seus postulados de integração dos indivíduos na diversidade social e do papel da escola no processo de socialização dos indivíduos nos valores do convívio coletivo?
}

Retomando a origem do conservadorismo clássico, identificamos a Revolução Francesa como um novo estágio de constituição da mentalidade ocidental, por um lado, estabelecendo as condições históricas para o conservadorismo, por outro, pois se torna objeto de críticas de Edmund Burke ${ }^{9}$, em suas Reflexões sobre a Revolução na França, obra publicada em 1790, imediatamente após o desencadeamento do processo revolucionário, tendo sido bem

9 Edmund Burke nasceu em 12 de janeiro de 1729 na cidade de Dublin (Irlanda) e faleceu em Beaconsfield (Reino Unido) no dia 9 de julho de 1797. Filósofo e político anglo-irlandês. Informações contidas na orelha do livro Reflexões sobre a revolução na França, de Edmund Burke, Editora Edipro (2014).

\begin{tabular}{|l|l|l|l|l|}
\hline Rovista Dialectus & Ano 10 & n. 23 & Maio - Agosto 2021 & p. $279-306$ \\
\hline
\end{tabular}


recebida pelos setores intelectuais ligados à reação antirrevolucionária, mas também foi objeto de crítica dos revolucionários, dos moderados aos radicais, incluindo entre os críticos, ainda, Karl Marx, que atribuiu a Burke os adjetivos de sofista e sicofanta, conforme aponta Souza (2016, p. 363).

Na visão de Burke, conforme salienta Souza (2016, p. 365), os acontecimentos de 1789 foram “[...] um atentado ao mais elevado patamar civilizacional que a humanidade já havia alcançado: as instituições e tradições do antigo regime". Assim, “[...] as concepções de igualdade, direitos do homem, razão, antropocentrismo, liberdade individual, soberania popular, são identificadas como ideias perigosas à ordem estabelecida [...]” (Idem, p. 367).

Para Burke, citado por Souza (2016, p. 370), “[...] seria papel da nobreza e dos mais altos signatários das classes dominantes a realização das mudanças políticas na França, não dos setores dominados da sociedade". Considerava, também, os membros das classes trabalhadoras "homens feitos para serem instrumentos e não para exercer um controle" (Idem, ibidem).

Em se tratando do ressurgimento das ideias ultraconservadoras, Frigotto (2018, p. 21) indica o "colapso do socialismo real e a apropriação de um novo salto tecnológico pelo capital" como fatores que contribuíram, sobremaneira, para o "desenvolvimento do pensamento único, o abandono das teses da inclusão e a retomada do pensamento ultraconservador, cunhado de "neoliberalismo"'. Em se tratando de sociedades de capitalismo dependente, como o Brasil, que manteve quatro séculos de escravidão, “ampliam-se as posturas autoritárias e neofascistas [...]". Como exemplo, Frigotto (2018, p. 23) cita o golpe de 2016, por meio do qual se violam o "Estado de direito e a frágil democracia".

Partimos do pressuposto de que estamos sob a vigência de uma situação reacionária aberta com o impeachment da ex-presidenta Dilma Rousseff, caracterizado, em nossa opinião, como um golpe parlamentar, mas que vem se aprofundando desde então, com a ascensão de Michel Temer à Presidência da República e, posteriormente, com a vitória de Jair Bolsonaro como seu sucessor e a reconfiguração do parlamento brasileiro, assumindo características cada vez mais ultraconservadoras.

Calil (2019) elenca os elementos que constitui um núcleo ideológico reacionário, a saber, "anticomunismo, ultranacionalismo, antipolítica, militarismo, armamentismo, culto da violência, mitificação do líder, misoginia, criação sistemática de inimigos, disseminação do ódio aos direitos humanos".

No campo da educação, o EsP ilustra essas posturas pelo "caráter reacionário em que assentam as teses do movimento" (FRIGOTTO, 2018, p. 18) que leva o seu nome. Frigotto

\begin{tabular}{|l|l|l|l|l|}
\hline Govista Dialectus & Ano 10 & n. 23 & Maio - Agosto 2021 & p. 279 - 306 \\
\hline
\end{tabular}


(2018, p. 15), ao analisar o caráter do movimento EsP, explicita que, contrariando o próprio discurso de efetivação de uma escola sem partido, “[...] busca instrumentalizar a escola para naturalizar a face mais violenta e excludente das relações sociais capitalistas e que se expressa na sociedade brasileira historicamente com as marcas do autoritarismo e da violência".

Saviani (apud HERMIDA; LIRA, 2018, p. 784) identifica o projeto Escola sem Partido como "componente da onda reacionária [...]" que vem tomando proporções nos últimos anos no Brasil e complementa o raciocínio explicando que a defesa de uma educação "[...] isenta de influência política é uma forma eficiente de colocá-la a serviço dos interesses dominantes". Para o autor,

[...] é esse o sentido do programa "Escola sem Partido", que visa, explicitamente, subtrair a escola do que seus adeptos entendem como "ideologias de esquerda", colocando-a sob a influência da ideologia e dos partidos da direita, portanto, a serviço dos interesses dominantes $[\ldots]$.

O autor (apud HERMIDA; LIRA, 2018, p. 785) também denuncia a própria denominação "Escola sem Partido", uma vez que

[...] camufla, pois, o fato de que se trata da escola dos partidos da direita, os partidos conservadores e reacionários que visam manter a situação vigente com todas as injustiças e desigualdades que caracterizam a forma de sociedade dominante no mundo de hoje.

Conti e Piolli (2019, p. 293), na mesma direção, situam o fortalecimento do EsP no contexto do avanço das ideias autoritárias no Brasil, que refletem, de acordo com os autores, "[...] a intolerância, o clamor ao autoritarismo, o discurso do ódio às diferenças" e "remete à cultura do medo". Na escola, esse clima se reproduz "[...] na forma de cerceamento ao livre pensamento e ao ensino crítico da ciência o que só pode ocorrer numa escola onde a autonomia e a participação de estudantes e professores são elementos centrais do processo pedagógico". (CONTI; PIOLLI, 2019, p. 294-295).

De uma forma geral, Carvalho (2019, p. 61) analisa o EsP sob a ótica da conjuntura e da situação que se abriu no país com o golpe de 2016, constituindo-se “[...] parte do movimento político que a direita realiza em sua busca para consolidar o golpe de 2016”. Para tanto, o EsP atua

\begin{tabular}{|l|l|l|l|l|}
\hline Q & Ano & Maio - Agosto 2021 & p. $279-306$ \\
\hline
\end{tabular}


[...] no plano político no campo das disputas pela hegemonia do discurso que a direita trava e que se manifesta na crítica aos processos de regulação estatal dos processos educacionais, especificamente curricular, na imposição de uma fratura entre formação e escolarização, no ataque aos movimentos sociais que atuam na construção de políticas de identidade, gênero, étnicas, raciais e sexuais [..]. (CARVALHO, 2019, p. 61-62). (grifos nossos).

Na mesma direção, Silva Jr. e Fargoni (2019, p. 72), consideram que o EsP é “um plano reacionário [...] que tem a intenção de ceifar o exercício pedagógico", corroborado por Orso (2019, p. 159), que o caracteriza como “[...] um movimento extremamente conservador e violento [...] que se escuda no suposto 'direito dos pais de educarem seus filhos' e no suposto combate à 'ideologia de gênero"”.

Em sintonia com os autores citados, Silveira e Orso (2019, p. 252) categorizam o EsP como movimento "[...] de caráter liberal-conservador, alinhado aos interesses da classe dominante", que defende sob o manto do discurso da neutralidade, escamoteia "[...] o objetivo de transformar a escola numa espécie de partido único, adequada à burguesia”. Rosa (2018, p. 55) complementa dizendo que as ações do EsP seriam “[...] respostas conservadoras aos avanços democráticos das ultimas décadas" (ROSA, 2018, p. 55).

$\mathrm{O}$ mesmo discurso encontra-se no Manifesto à Nação da Frente Parlamentar Evangélica que afirma ser necessário "libertar a educação pública do autoritarismo da ideologia de gênero, da ideologia da pornografia [...]" (grifos nossos) (2018, p. 54). Tal documento, de caraterísticas ultraconservadoras do ponto de vista da ideologia e da moral, reivindica o documento do Banco Mundial (BM) Um ajuste justo: Análise da eficiência e equidade do gasto público no Brasil (2017) e suas proposições ultraliberalizantes relativas ao enxugamento dos chamados gastos públicos, especificamente, os vinculados constitucionalmente, como, no caso da educação.

Fontes (2016, p. 16) destaca que, nas ultimas décadas, tem crescido o predomínio patronal direto sobre as escolas públicas, assim como aumentado a "industrialização da educação" (grifos da autora), processo que ocorre por meio da "privatização direta" e da "modificação da escola pública", isto é, nas palavras de Fontes, "um extensíssimo processo de deseducação pública generalizada (no público e no privado)”. Sentencia (2016, p. 17): “Ao implantar tal predomínio, pretendem ao mesmo tempo lucrar e silenciaras tensões constitutivas da escola, [...] eliminando qualquer concepção crítica (e até mesmo qualquer voz contraditória) [...]". A autora (2016, p. 18) apresenta o movimento Escola sem Partido como um "exemplo gritante de proposta explícita de deseducação, ou de imposição da censura direta sobre o processo de socialização do conhecimento". 
Freitas (2018, p. 28), em sintonia com a análise feita por Fontes (2016), chama a atenção para o fato de que seria, então, nessa linha de raciocínio,

[...] compreensível que movimentos destinados a cercear a liberdade docente como o 'Escola sem Partido' [...] estejam simultaneamente presentes à implementação acelerada das reformas constitucionais e do Estado, após 2016, incluindo a reforma da educação, com autoria e financiamento empresarial. Tais iniciativas têm a mesma origem ideológica: o neoliberalismo [...].

Saviani (2017), seguindo a mesma lógica dos autores anteriores, afirma que a ofensiva da direita sobre a educação teria dois componentes, a saber:

O primeiro é de caráter global e tem a ver com a fase atual do capitalismo que entrou em profunda crise de caráter estrutural, situação em que a classe dominante, não podendo se impor racionalmente precisa recorrer a mecanismos de coerção combinados com iniciativas de persuasão que envolvem o uso maciço dos meios de comunicação e a investida no campo da educação escolar tratada como mercadoria e transformada em instrumento de doutrinação.

O segundo componente tem a ver com a especificidade da formação social brasileira marcada pela persistência de sua classe dominante sempre resistente em incorporar a população temendo a participação das massas nas decisões políticas. É essa classe dominante que agora, no contexto da crise estrutural do capitalismo, dá vazão ao seu ódio de classe mobilizando uma direita raivosa que se manifesta nos meios de comunicação convencionais, nas redes sociais e nas ruas.

As terminologias movimento conservador e movimento reacionário utilizados pelos(as) autores(as)s assumem o mesmo sentido enquanto categoria para se referir à natureza do EsP como um movimento que está em sintonia com o momento vivenciado no País, marcado pela ascensão de um governo de extrema-direita e de avanço de forças autoritárias que atacam os direitos sociais e as liberdades democráticas do conjunto da classe trabalhadora.

\section{DOUTRINAÇÃO}

Para o EsP, a escola seria um instrumento de "doutrinação" ideológica que difunde, por meio do(a) professore(a), uma ideologia de esquerda e de gênero, o qual “[...] é tachado de doutrinador como sendo o inimigo de última hora [...]" (QUEIROZ; OLIVEIRA, 2018, p. 38). Queiroz e Oliveira (2018), Ramos (2018), Conti e Piolli (2019), Carvalho (2019), Martins (2019), Orso (2019) e ANDES-SN (2020) tratam dessa categoria situando-a no debate sobre o papel que a escola vem cumprindo desde a sua origem.

\begin{tabular}{|l|l|l|l|l|}
\hline Q & Ano 10 & n. 23 & Maio - Agosto 2021 & p. 279 - 306 \\
\hline
\end{tabular}


Ramos (2018, p. 7) explicita que o EsP teria escolhido como "síntese de suas antíteses o termo 'doutrinação' e o que denominaram como 'ideologias' de esquerda e de gênero". (grifos nossos). A doutrinação, na perspectiva do EsP, é identificada com pensamento crítico e o/a professor/a é considerado/a inimigo/a. O discurso da "ideologia de gênero", por sua vez, só poderá ser captado no seu real significado se for analisado à luz do avanço do movimento ultraconservador em curso no Brasil e que, especificamente, se dirige contra a discussão de gênero na escola, consistindo uma "cruzada ofensiva antigênero" (RAMOS, 2018, p. 9).

A pergunta que não quer calar. A escola é doutrinadora? Primeiramente, interessanos definir doutrinação, já que os documentos do EsP acusam o(a)s professore(a)s de doutrinadore(a)s, sem apresentar qualquer definição de doutrinação. Conforme Martins (2019, p. 103), doutrinação

[...] pode ser concebida como um processo social que incute ideias, valores, concepções de mundo, normas de comportamento em um indivíduo ou em um conjunto deles por meios autoritários, que não aceitam questionamentos de qualquer ordem.

Desde quando a instituição escolar foi criada na Grécia Antiga, há mais de 2,5 mil anos, tem se constituído "[...] no principal meio de produção, preservação e socialização do conhecimento científico" (ORSO, 2019, p.131) e também refletido na forma e no conteúdo os interesses das classes dominantes em cada época, tendo na sua origem a marca do escravismo, uma vez que se caracterizava por ser o "lugar do ócio", portanto, daqueles que não tinham o que fazer, ou seja, os senhores de escravos.

Isso significa que a doutrinação na escola existe desde seu surgimento, mas não tem sido uma doutrinação da esquerda, mas das classes dominantes. Entretanto, com o advento do capitalismo, a escola passa a ser disputada pela classe trabalhadora, constituindo-se numa necessidade do capital para formação da mão de obra e disseminação dos valores da modernidade, mas também uma necessidade dos(as) trabalhadores(as) de se apropriarem do conhecimento historicamente construído para se situarem na sociedade contratual, letrada, urbana e, também, como cidadãos e cidadãs de direitos e deveres.

Na mesma linha, a cartilha do ANDES-SN ressalta que

[...] a doutrinação e o partidarismo que os projetos [EsP] dizem combater estão presentes desde a origem da escola, na sua função social, no currículo oficial e oculto, nos conteúdos e discursos, na hierarquia, na disciplina, na avaliação, enfim, nas

\begin{tabular}{|l|l|l|l|l|}
\hline Q & Ano 10 & n. 23 & Maio - Agosto 2021 & p. 279 - 306 \\
\hline
\end{tabular}


relações estabelecidas no seu interior. Então, a doutrinação ideológica que o ESP afirma combater não é aquela que esteve sempre presente na escola [...] (ANDES-SN, 2020, p. 15-16).

A cartilha complementa afirmando que, na verdade, o EsP combate os conhecimentos que nascem das "[...] contradições que permeiam a escola como um espaço de disputa de projetos" (ANDES-SN, 2020, p. 16). Nesse momento, surge um problema para a classe dominante:

[...] como fazer para difundir a escola, já que se constituía numa necessidade de desenvolvimento da nova classe dominante, porém, sem correr o risco de perder o controle sobre ela? Afinal, se a escola havia sido criada para reproduzir os conhecimentos da classe dominante para perpetuar a sua dominação, a apropriação dos mesmos pelos integrantes da classe que lhe era oposta, os trabalhadores, poderia se tornar perigosa (ORSO, 2019, p. 132).

A solução seria manter a escola pública, gratuita, laica, sob o controle do Estado, no caso, o burguês, reivindicação democrático-liberal, mas, bifurcá-la, criando uma escola rica para os(as) filhos(as) da classe dominante e uma escola pobre para os(as) filhos(as) dos(as) trabalhadores(as).

Como Carvalho (2019, p. 64) destaca a respeito do papel da escola, o qual "[...] não tem sido o de disseminar a lógica da solidariedade e da igualdade, pelo contrário, a escola tem sido aquela que, em uma sociedade que naturaliza a desigualdade, encontra os melhores alunos, os reconhece e legitima socialmente".

Os regimes políticos autoritários usaram e usam um variado arsenal de instrumentos e formas de doutrinação, sendo a escola um meio privilegiado para cumprir tal objetivo, a exemplo da ditadura empresarial-militar no Brasil, que lançou mão de diversas reformas educacionais e implantou leis cerceadoras das liberdades democráticas, inclusive no interior das escolas e universidades.

Martins (2019, p. 102) destaca que o EsP teria uma pauta centrada em duas questões: “[...] acabar com a alegada 'doutrinação político-ideológica nas escolas' e defender que a educação moral e religiosa das crianças ocorra exclusivamente nas famílias, sem intervenções das escolas, particularmente dos professores e professoras".

Essa defesa de que os pais têm o direito de educar conforme seus valores, ou seja, seguindo a máxima "meus filhos, minhas regras" pressupõe a efetiva doutrinação políticoideológica no interior das escolas, enquadrando “[...] os professores como militantes e doutrinadores quando esses promovem, em sala de aula, situações de aprendizagem que levam

\begin{tabular}{l|l|l|l|l|l|} 
Q & Ano 10 & n. 23 & Maio - Agosto 2021 & p. 279-306 \\
\hline
\end{tabular}


os alunos a questionarem seus valores e problematizarem sobre realidade". (CONTI; PIOLLI, 2019, p. 302).

Um dos temas contra o qual o EsP se insurge e caracteriza como doutrinação ideológica é a chamada "ideologia de gênero", como veremos a seguir.

\section{GENÊRO E "IDEOLOGIA DE GÊNERO"}

Nesse momento, tratamos das categorias "gênero" e a chamada "ideologia de gênero" contando com as elaborações de Marafon e Souza (2018), Conti e Piolli (2019) e Rossi e Pátaro (2018), baseados nas obras do(as) autores(as) estudados(as).

O primeiro aspecto a ser observado em torno do debate sobre "ideologia de gênero" é saber exatamente o significado que essa expressão carrega e a que se referem quando os apologistas do EsP acusam a escola, os(as) professores(as) de disseminarem uma suposta “ideologia de gênero". A discussão não tem uma base real, uma vez que não existe na literatura que trata das questões de gênero nas suas mais diversas facetas nada que se aproxime de uma "ideologia de gênero" sendo, portanto, uma categoria criada pelo campo reacionário para desqualificar e retroceder os pequenos avanços conquistados nessa área e imprimir "[...] um rótulo que denomina de forma pejorativa toda uma discussão teórica e política desenvolvida pelo movimento feminista e LGBT cujo objetivo é desconstruir estereótipos que excluem e violentam aqueles que fogem do padrão moral hegemônico". (CONTI; PIOLLI, 2019, p. 299).

Primeiramente, Marafon e Souza (2018, p. 75) situam a origem do termo gênero tomando como referencia as contribuições de Haraway (2004).

[...] o conceito gênero foi construído nos anos 1950 [...] no interior do campo (psico)médico por autores com John Money, Anke Ehrhardt e, posteriormente, Roberto Stoller, tendo aspecto normalizante, situado no paradigma da identidade de gênero. [...] o conceito gênero foi reapropriado por perspectivas feministas mais críticas e de outros movimentos sociais, ao mesmo tempo que recebia reconhecimento e formalização em espaços acadêmicos. [...] 'Gênero é um conceito desenvolvido para contestar a naturalização da diferença sexual em múltiplas arenas de luta' (HARAWAY, 2004, p. 211).

Marafon e Souza (2018, p.76) informam que o discurso da "ideologia de gênero" teria sido arquitetado "como reação às discussões ocorridas para aprovação dos documentos da Conferência Internacional sobre População, no Cairo, em 1994, e da Conferência Mundial sobre as Mulheres, em Pequim, no ano seguinte". Na ocasião, o Vaticano “convocou 'especialistas'

\begin{tabular}{|c|c|c|c|c|}
\hline Qovista Dialectus & Ano 10 & n. 23 & Maio - Agosto 2021 & p. $279-306$ \\
\hline
\end{tabular}


para por em marcha uma 'contraofensiva' que reafirmava a doutrina católica e reiterava a naturalização na ordem sexual centrada na dominação masculina e na matriz heterossexual".

Outro conceito que ignora a realidade social, conforme salienta Carreira (2016), referido por Rossi e Pátaro (2018), é a noção de família usada pelo EsP, que "está limitada unicamente ao modelo nuclear - formado por pai, mãe e filhos/as" (ROSSI; PÁTARO, 2020, p. 12). Fecham os olhos para não enxergar o que, atualmente, caracteriza a família brasileira, marcada por "arranjos familiares - com mães ou pais solos, famílias lideradas por avôs e avós, famílias de casais homoafetivos, dentre outras" (p. 12).

Os estudos de Sevilla e Seffner (2017) e de Ferreira e Alvadia Filho (2017), revisados por Rossi e Pátaro (2018), revelam que as concepções de gênero do EsP se situam "dentro de um contexto articulado a outras demandas de caráter político-religioso e conservador", como, por exemplo, o PL no 6.583, conhecido como o "Novo Estatuto da Família", "o qual visava o reconhecimento do padrão heteronormativo como o único modelo de família legalmente reconhecido pelo Estado". (ROSSI; PÁTARO, 2020, p. 12).

Podemos afirmar, com base nessas informações, que está em curso uma "cruzada ofensiva antigênero", que fomenta preconceitos e discriminações e ataca os princípios da promoção da igualdade, "gestada no interior do discurso e de práticas católicas fundamentalistas, tendo sido apropriado por setores ultraconservadores [...]" (MARAFON; SOUZA, 2018, p. 75).

Marafon e Souza (2018, p. 81) concluem que, além der ser uma manifestação antigênero, o EsP “[...] é um movimento antidemocrático. [...] é um movimento que contribui para a manutenção de privilégios de alguns e para a perpetuação de práticas preconceituosas, segregacionistas e violentas contra muitos outros".

\section{CRIMINALIZAÇÃO DOS(AS) PROFESSORES(AS)}

O debate sobre doutrinação está imediatamente ligado a uma visão desqualificadora dos(as) professores(as), os quais são considerados(as) responsáveis não apenas pela contaminação politico-ideológica, mas também pela crise educacional, criando um clima de “criminalização dos(as) professores(as)”. Orso (2019), Costa e Velloso (2018) e Penna (2018) desenvolvem essa categoria. 
Por que a escola vai mal e os alunos não aprendem? Para o EsP, “[...] isso acontece porque, ao invés de 'ensinar' os professores se aproveitam da presença (cativa) dos alunos para doutrinar e impor suas ideologias”. (ORSO, 2019, p. 143).

O EsP promove uma cultura de desconfiança do(a) professor(a), descaracteriza o trabalho docente e desqualifica o(a) profissional da educação no exercício de sua função - a de educar. $\mathrm{O}(\mathrm{a})$ aluno(a), na perspectiva do EsP, também é rebaixado(a), uma vez que é concebido(a) como uma "tábula rasa" ou uma folha em branco.

Assim, aponta a fala do(a) professor(a) como "explicação ideológica em sentido negativo, como se outros conhecimentos não o fossem. [...] para eles, são temas ideológicos gênero, religiões de matriz africana, desigualdade social, movimentos sociais" (COSTA; VELLOSO, 2018, p. 140).

O EsP, ao identificar a fala do(a) professor(a) como uma "fala ideológica", caracteriza-o(a) como “[...] militante disfarçado, abusador, estuprador, sequestrador intelectual” (PENNA, 2018, p. 114). Na mesma direção, aponta a caracterização da Frente Parlamentar Evangélica, já citada aqui, de que acusa os(as) 'professores(as) de promoverem em sala de aula uma "ideologia de gênero" e uma "ideologia da pornografia" (2018, p. 54).

Percebe-se que o modus operandi do EsP é "fomentar uma estrita desconfiança e vigilância contra a atividade docente", uma vez que os(as) professores(as) são visto(a)s "como inimigos com os quais não se deve dialogar" (PENNA, 2018, p. 116).

Nagib (2017), em audiência pública, ao se referir ao argumento dos críticos de que o aluno não é uma folha em branco, responde de forma agressiva identificando os(as) docentes como

[...] abusadores que procuram minimizar a gravidade dos seus atos apelando para a condição pessoal das suas vítimas (...) E digo mais: é um argumento também típico dos estupradores que alegam em sua defesa que aquela menina de doze anos, que eles acabaram de violentar, não é tão inocente quanto parece. Este é o argumento de que o aluno não é uma folha em branco. (apud SALLES; SILVA, 2018, p. 161). (grifo nosso).

Nessa passagem se revela o ódio à(o) professor(a), que é visto(a) não apenas como doutrinador(a), acusação que, por si só, já é grave, mas também como inimigo, abusador e estuprador, além de promover uma "ideologia da pornografia", na opinião da Frente Parlamentar Evangélica (2018). Desqualificação e desvalorização da profissão docente em todos os sentidos, ou seja, econômica, social e moralmente.

\begin{tabular}{|c|c|c|c|c|}
\hline Qevista Dialectus & Ano 10 & n. 23 & Maio - Agosto 2021 & p. $279-306$ \\
\hline
\end{tabular}


O que o EsP pretende fazer com a escola é instituir uma cultura de pânico e terror, silenciar docentes e aluno(a)s e "[...] submetê-los a uma intensa, constante e ininterrupta coação, pressão, violência e tortura política, ideológica e mental com a finalidade de 'lobotomizá-los'. Com isso, sequestram o futuro dos estudantes, da educação e do país”. (ORSO, 2019, p. 155).

\section{IDEOLOGIA E NEUTRALIDADE}

Em síntese, de acordo com o EsP, as escolas seriam doutrinadoras de ideologias de esquerda, promovidas pelos(as) professores(as) doutrinadores(as) sobre os(as) alunos(as), que são manipulados(as). Dessa forma, distorce e simplifica o conceito de ideologia ao identificálo com a manipulação de estudantes. Concebida assim, a ideologia estaria relacionada "a um partidarismo de esquerda, que teria sempre o intuito de levar alunos(as) a aderirem a um determinado campo político" (ROSSI; PÁTARO, 2020, p. 7). Nesse momento, apresentamos a categoria "ideologia" com a ajuda de Rossi e Pátaro (2018), baseados nos(as) autores(as) revisados(as), os quais discutem essa categoria na sua relação com a categoria "neutralidade". A ideologia também foi abordada por Lessa (2019), na brochura Escola sem Partido e sociedade sem ideologias e discutida por Martins (2019).

Rossi e Pátaro (2020) revelam que ideologia e neutralidade são categorias que se encontram com mais frequência nos trabalhos analisados, o que indica, na opinião dos autores, que são "categorias centrais no discurso do ESP".

O fundador do Movimento Escola sem Partido (MEsP), o advogado Miguel Nagib, chegou à conclusão acerca do papel doutrinador das escolas e, por consequência dos(as) docentes, a partir de uma experiência vivenciada por sua filha na aula de história de uma escola particular, em que o professor teria comparado Che Guevara (um dos líderes da Revolução Cubana) com São Francisco de Assis (Santo da Igreja Católica), numa analogia às pessoas que abrem mão de tudo por uma ideologia, política e religiosa, respectivamente, o que considerou uma forma de doutrinação (EL PAÍS BRASIL, 2016).

Dessa maneira, surgiu o MEsP para combater aquilo que Nagib chama de doutrinação. "O ESP afirma publicamente que suas proposições são apartidárias e isentas de qualquer cunho ideológico, a partir do que defende um ensino neutro como estratégia de combate à suposta “doutrinação"” (ROSSI; PÁTARO, 2020, p. 7). (Grifos nossos).

Rossi e Pátaro (2020, p. 7), baseados no texto de Betto (2016), observam que, diferente daquilo que o MEsP diz sobre si mesmo, ele "pode ser compreendido, sim, como promotor de uma ideologia específica, na medida em que possui ideias que motivam suas

\begin{tabular}{|l|l|l|l|l|}
\hline Q Rovista Dialectus & Ano 10 & n. 23 & Maio - Agosto 2021 & p. 279 - 306 \\
\hline
\end{tabular}


ações". Os autores (2020, p. 7) revelam que Betto (2016) sugere "que se olhe para os defensores públicos do movimento, geralmente políticos de direita, líderes religiosos e membros conservadores da sociedade civil".

É importante abrir um parêntese para tratar do significado de ideologia, tomando como referencia a contribuição de Lessa (2019), o qual faz uma crítica à negação do caráter ideológico da escola e das ideias veiculadas por ela, pois, de acordo com o autor "as ideologias são conhecimentos e ideias que cumprem a função social de organizar como conjuntos de indivíduos atuam sobre os conflitos do seu dia a dia". Nessa perspectiva, o que torna as ideias, os conhecimentos ideológicos não é o fato de serem mais ou menos falsos, como proclamam os apologistas do EsP que associam ideologia a “[...] algo ruim, como uma coisa a ser eliminada da vida social" (LESSA, 2019, p. 5).

Em oposição às ideologias, defendem

[...] a fé no Deus cristão e a crença nos valores tradicionais da sociedade: a família monogâmica, patriarcal; a moral conservadora nos costumes, a disciplina na vida cotidiana, a propriedade privada burguesa como núcleo da liberdade; o Estado como ordenador da sociedade - e os deveres dos cidadãos como a aceitação desta ordenação social imposta pelo Estado (LESSA, 2019, p. 16).

Lessa $(2019,24)$ é categórico em afirmar que o "discurso contra as ideologias [...] nada mais é do que outra ideologia!" em consonância com a premissa freiriana "de que toda neutralidade afirmada é uma opção escondida".

Assim, o discurso contra a ideologia está relacionado com a defesa de uma suposta neutralidade da escola com a intenção de

[...] imprimir ao currículo uma ideologia mascarada como neutra e não ideológica, mas que, ao ser analisada, revela um favorecimento aos interesses de determinados grupos, pois impede que outros interesses sejam abordados na escola, geralmente de pessoas em situação de vulnerabilidade ou injustiça (RAMOS, 2017 apud ROSSI; PÁTARO, 2020, p. 5).

A categoria "neutralidade” é apresentada por Martins (2019) e Rossi e Pátaro (2020) na relação com a categoria ideologia, já apresentada no momento anterior. Mas o que é neutralidade, para o EsP? Os projetos da "Escola da mordaça" não apresentam um conceito de neutralidade rigorosamente formulado, mas a leitura deles deixa mais do que explícito, no corpo das proposituras e nas "justificativas", que se pretende vetar a discussão de alguns assuntos em

\begin{tabular}{|c|c|c|c|c|}
\hline Qovista Dialectus & Ano 10 & n. 23 & Maio - Agosto 2021 & p. $279-306$ \\
\hline
\end{tabular}


sala de aula, particularmente os que se referem à "moral sexual” e à política. (MARTINS, 2019, p. 10).

De qual moral sexual e de qual política o EsP está falando? De acordo, com Martins (2019, p, 10), “as que contrariam a visão antidemocrática do conservador movimento social”. Martins (2019) considera que a neutralidade proposta pelo EsP é impraticável, pois os projetos de lei

[...] querem se revestir de um a-politicismo, vendendo-se como não ideológicos e, portanto, neutros. Todavia, isso é impraticável, uma vez que estão a tratar de educação e esta se refere a processos de formação a que os indivíduos e grupos sociais são submetidos, seja na escola, seja em qualquer outro ambiente, visando a um ideal, que é eminentemente político. Isso é inexorável, pois ninguém nasce pronto. Todos e todas nascem inacabados, incompletos e a completude se faz por processo que são chamados de educativos. (MARTINS, 2019, p. 112).

Se a neutralidade é impraticável, então, o que significaria, de fato, reivindicar a neutralidade do conhecimento produzido e reproduzido na escola? Nas palavras de Martins (2019, p. 114), “[...] reivindicar a neutralidade política e ideológica é, justamente, deixar de ser neutro, é assumir um lado, abandonando qualquer imparcialidade".

Na perspectiva da neutralidade, o currículo assumiria uma natureza meramente técnica, reduzido "à função de transmissão de conteúdos, de preferência aqueles que são do interesse dos grupos que estão no poder e suas ideologias" (ROSSI; PÁTARO, 2019, p. 5), ou seja, "atenderia não só as expectativas de tal movimento, mas também de outros setores conservadores da sociedade que se unem a ele [...]” (p. 6).

\section{CURRÍCULO ESCOLAR}

Rossi e Pátaro (2020) discutem diversas nuances da categoria "currículo escolar" também identificada nos textos lidos, mas queremos chamar a atenção, especificamente, para a relação entre o EsP e a Base Nacional Comum Curricular (BNCC), destacada por Macedo (2017), citado por Rossi e Pátaro (2020, p. 4), que lembra que a BNCC "foi motivo de polêmicas e discussões, sobretudo pela retirada das menções aos termos 'identidade' e 'construção de gênero"”, expressões objeto de rejeição nos mais variados projetos de lei do EsP. É possível compreender essas relações entre BNCC e as proposições de uma escola "sem" partido situando o currículo escolar no âmbito das disputas de classes, culturais e ideológicas.

\begin{tabular}{|l|l|l|l|l|}
\hline Q Rovista Dialectus & Ano 10 & n. 23 & Maio - Agosto 2021 & p. 279 - 306 \\
\hline
\end{tabular}


A visão de um currículo técnico e aparentemente neutro e de uma escola que apenas instrui somada à vigilância cotidiana e persecutória de professores(as) "dilapida e ataca os pilares da escola democrática e os princípios constitucionais de garantia de direitos quanto à participação civil e de liberdade de expressão" (CARVALHO; POLIZEL; MAIO, 2016, p. 75 apud ROSSI; PÁTARO, 2020, p. 5). Nessa perspectiva, educação e instrução estão separadas.

\section{EDUCAR VERSUS INSTRUIR}

A categoria “educar versus instruir" é discutida por Silveira (2019), Penna (2017) e Orso (2019), o qual abre o texto com a seguinte questão: "Mas, qual o significado de educação para os fundadores, apoiadores e simpatizantes do MESP?".

Silveira (2019, p. 25) recorre a Penna (2017) para diferenciar os dois conceitos, na perspectiva do EsP:

[...] o ato de educar seria responsabilidade da família e da religião, enquanto o professor se limitaria a instruir, o que no discurso da Escola sem Partido equivale a transmitir conhecimento neutro, sem mobilizar valores e sem discutir a realidade social do aluno.

Para o EsP, o(a) professor(a) seria meramente um(a) instrutor(a) e não um(a) educador(a), pois, segundo Armindo Moreira, uma das principais referências para o EsP, "só educa eficazmente quem ama o educando. Exigir que o professor seja um educador é exigir que ele ame o aluno" e, complementa Moreira (2012, p. 11), “[o amor] não é sentimento que se exija para exercer uma profissão" (apud SILVEIRA, 2019, p. 25). Essa concepção de que o(a) professor(a) não é educador(a) fundamenta-se na premissa de que a escola deve ser neutra, bem como numa tentativa de transformá-la "num local de fomento do ódio, do machismo, de intolerância, de ignorância, de irracionalidade, de preconceitos e de todo tipo de retrocessos. É a institucionalização da barbárie”. (ORSO, 2019, p. 156).

A compreensão do EsP, seguindo a mesma lógica de Armindo Moreira, no livro Professor não é educador, contraria os ensinamentos de Paulo Freire de que a educação é um ato de amor e de coragem.

\section{IMPLICAÇÕES DO EsP PARA DOCENTES E DISCENTES}

\begin{tabular}{|c|c|c|c|c|}
\hline Qevista Dialectus & Ano 10 & n. 23 & Maio - Agosto 2021 & p. $279-306$ \\
\hline
\end{tabular}


Por fim, apresentamos, com base na literatura referida nesse trabalho, "as implicações do ESP para docentes e discentes", contando com a contribuição de Rossi e Pátaro (2020) e Lucena et al (2019).

As implicações para docentes e discentes são múltiplas e nefastas. "Os(as) primeiros(as) serão coagidos(as) e inibidos(as) na execução de sua profissão, por conta de todo o sistema de vigilância e punição que o movimento sugere para a escola" (ROSSI; PÁTARO, 2020, p. 14). Aos(às) alunos(as) serão negados(as) "uma formação que possa lhe oferecer subsídios mais sólidos” (p. 14) para desenvolver um pensamento crítico e autônomo.

Portanto, se o EsP for aprovado, silenciará "tanto as vozes docentes e discentes quanto os aprendizados oriundos da relação professor-aluno" (p.13) porque, na essência, o EsP “[...] materializa a instauração de princípios conservadores voltados à exclusão de todo e qualquer pensamento crítico nas escolas". (Lucena et al, 2019, p. 230).

\section{CONSIDERAÇÕES FINAIS}

Retomando o fio da meada, com base nas leituras realizadas e no diálogo com os autores e as autoras das obras e artigos revisados, podemos concluir, em termos gerais, que as produções científicas indicam que o EsP adotou como categorias centrais, além da defesa de uma suposta escola sem partido, a doutrinação ideológica e a chamada "ideologia de gênero" e de esquerda. Dessa forma, vê o(a) professor(a) como inimigo(a), o(a) qual estaria se aproveitando da audiência cativa do(a)s estudantes para ganhá-los para sua posição, ou seja, doutriná-los. O(a)s professore(a)s são visto(a)s como militantes de esquerda disfarçado(a)s, como se não fosse possível um(a) docente ter partido ou ser militante, condições que não são excludentes com relação ao exercício do magistério. Na proposta do EsP, além do(a) professor(a) ser visto(a) como inimigo(a), o estudante também é tratado como um sujeito sem discernimento.

Em nossa visão, o EsP encontra-se em sintonia com as propostas dos organismos do capital de privatização e mercantilização da educação, bem como ataca os princípios de liberdade de aprender e ensinar, pesquisar, divulgar o pensamento, pluralismo de ideias e concepções pedagógicas opondo-os a uma concepção baseada numa suposta neutralidade, caracterizando-se como um discurso / movimento reacionário, antidemocrático, autoritário e cerceador, como uma resposta às conquistas democráticas das ultimas décadas pós ditadura empresarial-militar no Brasil.

\begin{tabular}{|l|l|l|l|l|}
\hline Govista Dialectus & Ano 10 & n. 23 & Maio - Agosto 2021 & p. 279 - 306 \\
\hline
\end{tabular}


O surgimento da proposta de uma "escola sem partido" se situa no contexto de avanço das ideias ultraconservadoras e autoritárias no país, que podem ser resumidas em elementos "como a transferência da educação para a alçada da família; o repúdio a um suposto viés ideológico de esquerda que permearia as escolas; a oposição às discussões sobre diversidade cultural e a denominada ideologia de gênero", como acentuam Costa e Velloso (2018, p. 146).

Em termos pedagógicos, o EsP pensa a escola como espaço de reprodução de conteúdos, o(a) professor(a) como transmissor e o(a) aluno(a) como mero(a) receptor(a). A escola seria um lugar "neutro" que ensinaria apenas o conteúdo técnico entendido como qualificação para o trabalho. No limite, essa concepção inviabiliza o próprio pensamento científico.

Além da disputa ideológica travada pelo EsP em defesa de uma escola sem partido e ideologias, também faz a disputa junto ao poder legislativo, seja ele nos âmbitos federal, estaduais ou municipais, por meio da apresentação de PL na Câmara dos Deputados, nas casas legislativas e câmaras municipais de vários estados e municípios, respectivamente, como mostrou o mapeamento realizado por Moura e Silva (2020).

Outro aspecto da luta política e ideológica e jurídica se dá em torno da chamada "ideologia de gênero", do gênero, da diversidade e orientação sexual, aproximando o EsP de outros movimentos com ideologias bem definidas, como a Frente Parlamentar Evangélica, ao próprio governo Bolsonaro, aos partidos de direita e extrema direita, embora se autodenomine apartidário.

Consideramos, com ajuda de Martins (2019, p. 122-123), que não poderíamos chegar à outra conclusão sobre a “[...] 'Escola da mordaça' senão a que a entende como partido e um partido reacionário [...]", partindo da compreensão de partido como um grupo que se mobiliza “[...] em torno de uma visão de mundo, que expressa orientações à prática social e que é socializada por diferentes meios, com o intuito de educar-cooptar indivíduos, grupos e organizações sociais para suas "fileiras"” e, sobretudo, "disputar o poder político" e "dirigir o aparelho do Estado".

O EsP traz, em seus pressupostos, muito da doutrinação que afirma combater, caracterizando-se por ser um movimento/projeto/programa essencialmente ideológico, mas uma ideologia de direita, que pretende manter o status quo da sociedade capitalista.

\section{REFERÊNCIAS}

\begin{tabular}{|l|l|l|l|l|}
\hline Govista Dialectus & Ano 10 & n. 23 & Maio - Agosto 2021 & p. 279-306 \\
\hline
\end{tabular}


AÇÃO EDUCATIVA (Org.). A ideologia do movimento Escola sem Partido: 20 autores desmontam o discurso. São Paulo: Ação Educativa, 2016.

ANDES-SN. Projeto do capital para a educação: análise e ações para a luta. V. 3. Brasília (DF): ANDES-SN, 2020.

MUNDIAL, Banco. Um ajuste justo: Análise da eficiência e equidade do gasto público no Brasil. Volume 1: Síntese. Brasil, novembro de 2017. Disponível em: http://documents.worldbank.org/curated/en/884871511196609355/pdf/121480-REVISED-

PORTUGUESE-Brazil-Public-Expenditure-Review-Overview-Portuguese-Final-revised.pdf. Acesso em: 30/04/2020.

BATISTA, Eraldo Leme; ORSO, Paulino José; LUCENA, Carlos (Org.). Escola sem Partido ou escola da mordaça e do partido único a serviço do capital. Uberlândia: Navegando Publicações, 2019.

BRASIL. Lei 9.394/96. Estabelece as diretrizes e bases da educação nacional. 1996. Disponível em: http://www.planalto.gov.br/ccivil_03/leis/L9394.htm. Acesso em: 25/03/2020.

BRASIL. Câmara dos Deputados. PL No 7180/2014. Altera o art. $3^{\circ}$ da Lei no 9.394, de 20 de dezembro de 1996. (Programa Escola Sem Partido). 2014. Disponível em: http://www.camara.gov.br/proposicoesWeb/fichadetramitacao?idProposicao=606722. Acesso em: 24/03/ 20.

BRASIL. Câmara dos Deputados. PL No 867/2015. Inclui, entre as diretrizes e bases da educação nacional, o "Programa Escola sem Partido". 2015. Disponível em: https://www.camara.leg.br/proposicoesWeb/fichadetramitacao?idProposicao=1050668.

Acesso em: 30/04/2020.

BRASIL. Constituição de República Federativa do Brasil de 1988. Disponível em: http://www.planalto.gov.br/ccivil_03/constituicao/constituicaocompilado.htm. Acesso em: 25/03/2020.

BURKE, Edmund. Reflexões sobre a revolução na França. Tradução José Miguel Nanni Soares. São Paulo: Edipro, 2014.

CARVALHO, Celso. O discurso de despolitização como meio de politização da educação: a ação ideológica do movimento Escola sem Partido. IN: BATISTA, Eraldo Leme; ORSO, Paulino José; LUCENA, Carlos (Org.). Escola sem Partido ou escola da mordaça e do partido único a serviço do capital. Uberlândia: Navegando Publicações, 2019. 
CONTI, Mariana; PIOLLI, Evaldo. O movimento Escola sem Partido e o "cemitério dos vivos": a proposição da lei e a resistência em Campinas. In: BATISTA, Eraldo Leme; ORSO, Paulino José; LUCENA, Carlos (Org.). Escola sem Partido ou escola da mordaça e do partido único a serviço do capital. Uberlândia: Navegando Publicações, 2019.

COSTA, Carina Martins; VELLOSO, Luciana. "É que Narciso acha feio o que não é espelho": o ensinar e o aprender pela ótica do Escola sem Partido. IN: PENNA, Fernando; QUEIROZ, Felipe; FRIGOTTO, Gaudêncio (Org.). Educação democrática: antídoto ao Escola sem Partido. Rio de Janeiro: UERJ/LPP, 2018.

EL PAIS. BRASIL. O professor da minha filha comparou Che Guevara a São Francisco de Assis. Disponível em: https://brasil.elpais.com/brasil/2016/06/23/politica/1466654550_367696.html. Acesso em: $18 / 12 / 2020$.

FONTES, Virgínia. Formação dos trabalhadores e luta de classes. Trabalho Necessário, Ano 14, No 25/2016. Disponível em: http://periodicos.uff.br/trabalhonecessario/article/view/9618. Acesso em: 10/01/21.

FREITAS, Luiz Carlos de. A reforma empresarial da educação: nova direita, velhas ideias. São Paulo: Expressão Popular, 2018.

FRENTE PARLAMENTAR EVANGÉLICA. Manifesto à Nação: O Brasil para os brasileiros. Brasília, 2018. Disponível em: https://static.poder360.com.br/2018/10/Manifesto-a-Nacaofrente-evangelica-outubro2018.pdf. Acesso em: 24/03/2020.

FRIGOTTO, Gaudêncio (Org.). Escola sem Partido: esfinge que ameaça a educação e a sociedade brasileira. Rio de Janeiro: UERJ/LPP, 2017. Disponível em: https://www.academia.edu/37628475/ESCOLA_SEM_PARTIDO_Esfinge_que_amea\%C3\% A7a_a_educa\%C3\%A7\%C3\%A3o_e_a_sociedade_brasileira. Acesso em: 24/03/2020.

FRIGOTTO, Gaudêncio. A disputa da educação democrática em sociedade antidemocrática. IN: PENNA, Fernando; QUEIROZ, Felipe; FRIGOTTO, Gaudêncio (org.). Educação democrática: Antídoto ao Escola sem Partido. Rio de Janeiro: UERJ, LPP, 2018.

FRIGOTTO, Gaudêncio. Prefácio. IN: BATISTA, Eraldo Leme; ORSO, Paulino José; LUCENA, Carlos (Org.). Escola sem Partido ou escola da mordaça e do partido único a serviço do capital. Uberlândia: Navegando Publicações, 2019.

HERMIDA, Jorge Ferando; LIRA, Jailton de Souza. Políticas educacionais em tempos de golpe: entrevista com Dermeval Saviani. 2018. Disponível em: http://www.scielo.br/pdf/es/v39n144/1678-4626-es-39-144-779.pdf. Acesso em: 25/04/2020.

\begin{tabular}{|l|l|l|l|l|}
\hline Govista Dialectus & Ano 10 & n. 23 & Maio - Agosto 2021 & p. 279 - 306 \\
\hline
\end{tabular}


LESSA, Sérgio. Escola sem Partido e sociedade sem ideologias. Maceió: Coletivo Veredas, 2019.

LUCENA, Carlos et al. Da crítica emancipatória ao neocriticismo conservador - a escola sem partido. IN: BATISTA, Eraldo Leme; ORSO, Paulino José; LUCENA, Carlos (Org.). Escola sem Partido ou escola da mordaça e do partido único a serviço do capital. Uberlândia: Navegando Publicações, 2019.

MARAFON, Giovanna; SOUZA, Marina Castro. Como o discurso da "ideologia de gênero" ameaça o caráter democrático e plural da escola? IN: PENNA, Fernando; QUEIROZ, Felipe; FRIGOTTO, Gaudêncio (Org.). Educação democrática: antídoto a o Escola sem Partido. Rio de Janeiro: UERJ/LPP, 2018.

MARTINS, Marcos Francisco. "Escola sem Partido": um partido contra o direito de aprendizagem. IN: BATISTA, Eraldo Leme; ORSO, Paulino José; LUCENA, Carlos (Org.).

Escola sem Partido ou escola da mordaça e do partido único a serviço do capital. Uberlândia: Navegando Publicações, 2019.

MOURA, Fernanda Pereira de; SILVA, Renata da C. A. da. 6 anos de projetos "Escola sem Partido" no Brasil: levantamento dos projetos de lei estaduais, municipais, distritais e federais que censuram a liberdade de aprender e ensinar. Brasília: Frente Nacional Escola Sem Mordaça, 2020. Disponível em: https://www.escolasemmordaca.org.br/?p=4393. Acesso em: 01/12/2020.

MOURA, Fernanda Pereira de. O Movimento Escola sem Partido e a reação conservadora contra a discussão de gêneo na escola. IN: PENNA, Fernando; QUEIROZ, Felipe; FRIGOTTO, Gaudêncio (Org.). Educação democrática: antídoto a o Escola sem Partido. Rio de Janeiro: UERJ/LPP, 2018.

ORSO, Paulino José. Escola "sem" Partido ou um partido a serviço da burguesia? IN: BATISTA, Eraldo Leme; ORSO, Paulino José; LUCENA, Carlos (Org.). Escola sem Partido ou escola da mordaça e do partido único a serviço do capital. Uberlândia: Navegando Publicações, 2019.

PENNA, Fernando; QUEIROZ, Felipe; FRIGOTTO, Gaudêncio (Org.). Educação democrática: antídoto a o Escola sem Partido. Rio de Janeiro: UERJ/LPP, 2018.

PENNA, Fernando de Araújo. O Escola sem Partido como chave de leitura do fenômeno educacional. IN: FRIGOTTO, Gaudêncio (Org.). Escola "sem" Partido: Esfinge que ameaça a educação e a sociedade brasileira. Rio de Janeiro: UERJ, LPP, 2017.

\begin{tabular}{|l|l|l|l|l|}
\hline Govista Dialectus & Ano 10 & n. 23 & Maio - Agosto 2021 & p. 279 - 306 \\
\hline
\end{tabular}


PENNA, Fernando de Araújo. Construindo estratégias para uma luta pela educação democrática em tempos de retrocessos. IN: PENNA, Fernando; QUEIROZ, Felipe; FRIGOTTO, Gaudêncio (Org.). Educação democrática: antídoto a o Escola sem Partido. Rio de Janeiro: UERJ/LPP, 2018.

RAMOS, Marise Nogueira. Apresentação. IN: PENNA, Fernando; QUEIROZ, Felipe; FRIGOTTO, Gaudêncio (org.). Educação democrática: Antídoto ao Escola sem Partido. Rio de Janeiro: UERJ, LPP, 2018.

ROSA, Russel Teresinha Dutra da. Direito à educação democrática: conquistas legais e ameaças. IN: PENNA, Fernando; QUEIROZ, Felipe; FRIGOTTO, Gaudêncio (Org.). Educação democrática: antídoto a o Escola sem Partido. Rio de Janeiro: UERJ/LPP, 2018.

ROSSI, Jean Pablo Guimarães; PÁTARO, Ricardo Fernandes. A "lei da Mordaça" na literatura científica: Um estado da arte sobre o movimento Escola sem Partido. V. 36. Educação em Revista. Belo Horizonte, 2020. Disponível em: https://www.scielo.br/scielo.php?pid=S010246982020000100249\&script=sci_abstract\&tlng= pt. Acesso em: 02/12/2019.

SALLES, Diogo da Costa; SILVA, Renata da C. A. da. O Escola sem Partido na 305 desdemocratização brasileira. IN: PENNA, Fernando; QUEIROZ, Felipe; FRIGOTTO, Gaudêncio (Org.). Educação democrática: antídoto a o Escola sem Partido. Rio de Janeiro: UERJ/LPP, 2018.

SAVIANI, Dermeval. Escola sem Partido: O que isso significa? 2017. Disponível em: http://www.vermelho.org.br/noticia/301679-1. Acesso em: 25/04/2020.

SILVA JR. João dos Reis; FARGONI, Everton H. E. Escola sem partido: a inquisição da educação no Brasil. IN: BATISTA, Eraldo Leme; ORSO, Paulino José; LUCENA, Carlos (Org.). Escola sem Partido ou escola da mordaça e do partido único a serviço do capital. Uberlândia: Navegando Publicações, 2019.

SILVEIRA, Zuleide S. Onda conservadora: o emergente movimento escola sem partido. IN: BATISTA, Eraldo Leme; ORSO, Paulino José; LUCENA, Carlos (Org.). Escola sem Partido ou escola da mordaça e do partido único a serviço do capital. Uberlândia: Navegando Publicações, 2019.

SILVEIRA, Danielli Maria Neves da; ORSO, Paulino José. O movimento Escola “sem" Partido e a "doutrinação" liberal no atual contexto brasileiro. IN: BATISTA, Eraldo Leme; ORSO, Paulino José; LUCENA, Carlos (Org.). Escola sem Partido ou escola da mordaça e do partido único a serviço do capital. Uberlândia: Navegando Publicações, 2019.

\begin{tabular}{|l|l|l|l|l|}
\hline Govista Dialectus & Ano 10 & n. 23 & Maio - Agosto 2021 & p. 279 - 306 \\
\hline
\end{tabular}


SOUZA, Jamerson Murillo Anunciação de. Edmund Burke e a gênese conservadorismo. 2016.

Serv. Soc. Soc., São Paulo, n. 126, p. 360-377, maio/ago. Disponível em: http://www.scielo.br/pdf/sssoc/n126/0101-6628-sssoc-126-0360.pdf. Acesso em: 24/03/2020.

QUEIROZ, Felipe B. Campanuci; OLIVEIRA, Rafael Bastos Costa de. Liberdade para a democracia: considerações sobre a inconstitucionalidade da Escola sem Partido. IN: PENNA, Fernando; QUEIROZ, Felipe; FRIGOTTO, Gaudêncio (Org.). Educação democrática: antídoto ao Escola sem Partido. Rio de Janeiro: UERJ/LPP, 2018. 